\title{
\#USCS
}

\section{Cooperative Fish and Wildlife Research Units A Model Partnership Program}

T he U.S. Geological Survey (USGS) Cooperative Fish and Wildlife Research Units (CRU) program is a unique model of cooperative partnership among the USGS, other U.S. Department of the Interior and Federal agencies, universities, State fish and wildlife agencies, and the Wildlife Management Institute. These partnerships are maintained as one of the USGS's strongest links to Federal and State land and natural resource management agencies.

Established in 1935 to meet the need for trained professionals in the growing field of wildlife management, the program Ecurrently consists of 40 Cooperative Fish and Wildlife Research Units located on university campuses in 38 States and supports 119 research scientist positions when fully funded. The threefold mission of the CRU program is to (1) conduct scientific research for the management of fish, wildlife, and other natural resources; (2) provide technical assistance to natural resource managers in the application of scientific information to natural resource policy and management; and (3) train future natural resource professionals.

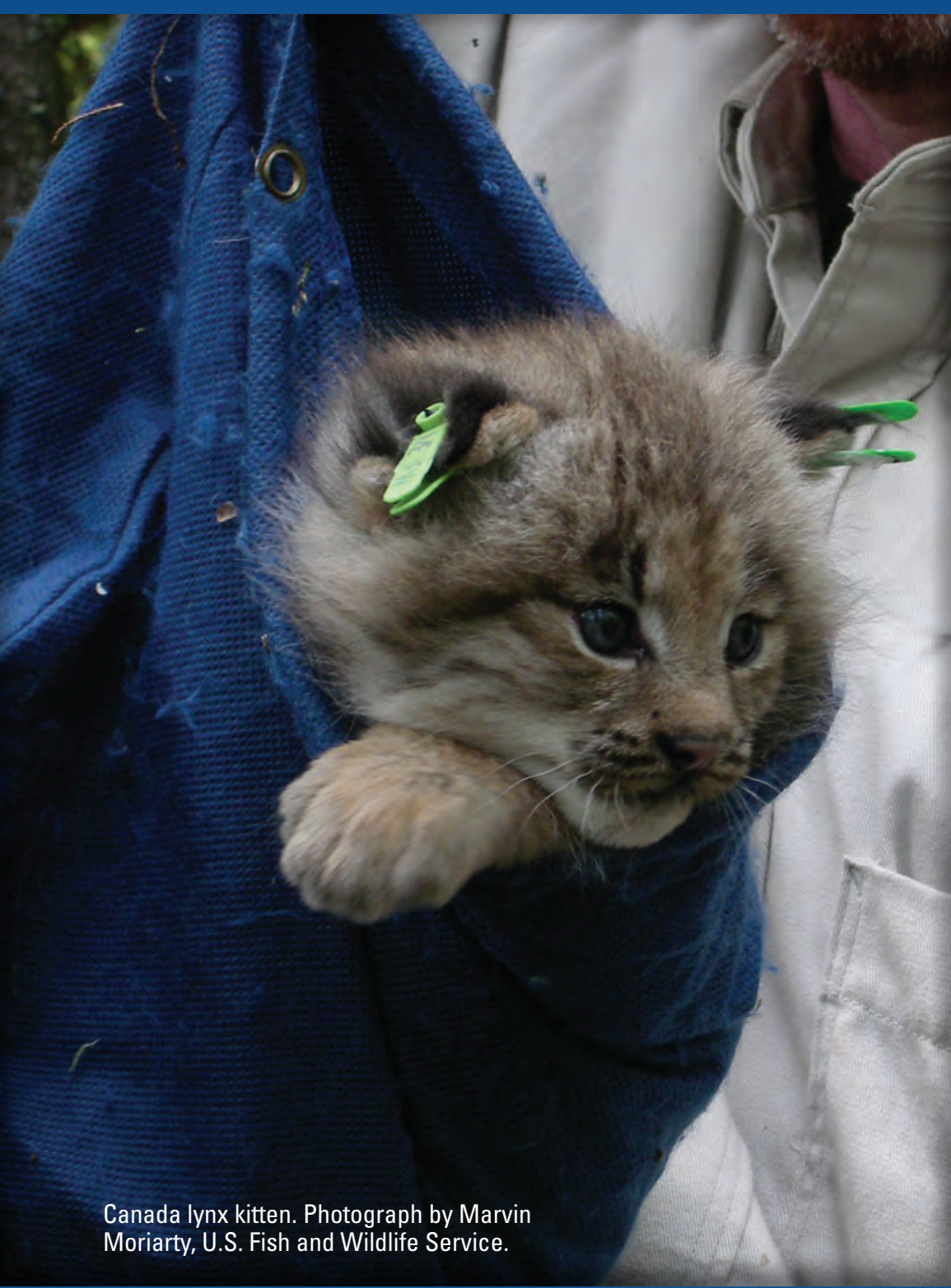

\section{Meeting USGS Strategic Goals and Objectives}

One of the three pillars of the CRU mission is to lead research that provides science solutions for the management needs of our State and Federal agency cooperators - research that informs decision making. The CRU program with its Federal, State, and university partners are proactively working together to conduct science at transboundary landscape levels to meet the needs of all stakeholders while building constructive, effective, geographically broad conservation programs that wouldn't be possible at the individual State level. The geographic distribution of the Units and the collaborative structure within the program place the CRU program in a unique role of facilitating these broader syntheses, analyses, and conservation efforts that fit neatly into larger USGS strategic goals and objectives, as evidenced below.

The breadth and scope of the CRU's research portfolio and scientific capacity is best demonstrated through USGS Circular 1427 titled "U.S. Geological Survey Cooperative Fish and Wildlife Research Units Program: 2016 Research Abstracts," which provides a summary of the objectives, findings, and applications of over 560 research projects that were active during fiscal year (FY) 2016.

The circular also highlights how CRU research efforts fulfill larger USGS strategic goals, specifically goals C and D of the Ecosystems Mission Area: "Science to Manage and Sustain Resources for Thriving Economies and Healthy Ecosystems" and "Accelerate Technological Innovation to Enhance Science-Based Decision Making." A summary of CRU research activities within the framework of the proposed 2018-22 USGS strategic goals and objectives is provided on the following pages. 
In 2016, over one-half of all Units were involved in specific research addressing Strategic Objective 4, focusing on the following science themes: Invasive Species (24 projects across 13 Units) and

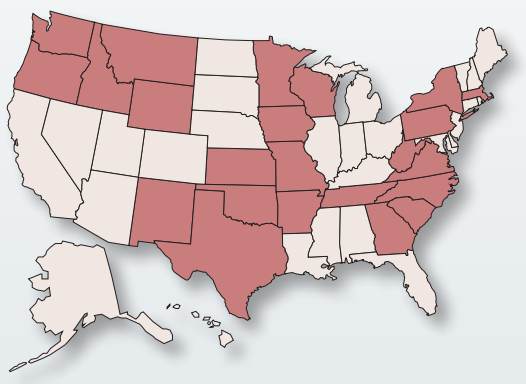

Figure 4. States with Cooperative Fish and Wildlife Research Units with 2016 research projects focusing on the science themes of Invasive Species and Wildlife Health and Disease.
Wildlife Health and Disease (36 projects across 21 Units).

Unit scientists throughout the program are involved in evaluating the effects of invasive species and wildlife disease as potential limiting factors in conservation and restoration efforts. For example, the Idaho Unit is looking at the effects sylvatic plague may be having in preventing the recovery and delisting of a federally threatened species:

Sylvatic plague is a bacterial disease of wild rodents that is transmitted by fleas. This study is documenting whether sylvatic plague is reducing survival of the federally threatened northern Idaho ground squirrel (Urocitellus brunneus brunneus). This project will complement an existing 10-year

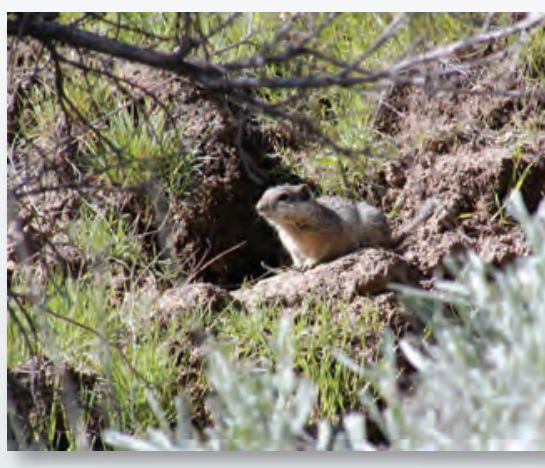

Northern ground squirrel image from the USFWS. study to evaluate the effectiveness of habitat restoration treatments at increasing populations of the squirrel. Study results will help managers working to reduce a potential threat (plague) that might be preventing population increases and thereby preventing recovery and delisting.

Strategic Objective 5: Critically Assess and Ensure Sustainable Use of Energy and Mineral Resources

In 2016, 12 Units were conducting 30 research projects involving energy-related activities, including solar energy, wind energy, and gas and oil extraction. A diverse set of taxa was evaluated and

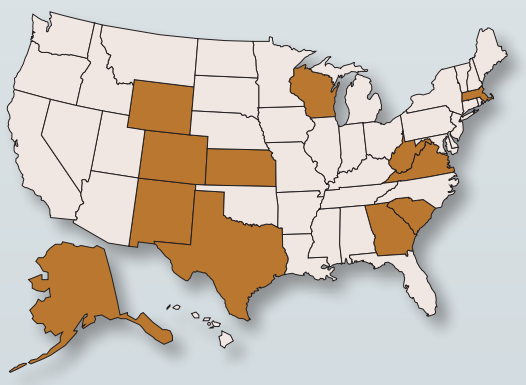

Figure 5. States with Cooperative Fish and Wildlife Research Units with 2016 research projects focusing on the science theme of Energy. included endangered or threatened raptors and other bird species, bats, ungulates, and a variety of aquatic species. In many cases, research emphasis was placed on determining the effect that energy projects had on the distribution and life-history traits of populations (at local and continental scales) to better inform decisions regarding siting and operation of energy projects, particularly to minimize potential negative effects of energy projects on their surroundings. For example, the following is a project summary from the New Mexico Unit:

Predicting the risk that proposed wind energy developments might have on resident and migratory golden eagles (Aquila chrysaetos) in southeastern and south-central New Mexico is hampered by a lack of information. This research is addressing critical information needs by assessing habitat and space use of migratory and resident golden eagles in areas managed by the Bureau of Land Management; identifying nest sites and estimating productivity and survival of golden eagles; determining patterns of relatedness for resident and wintering golden eagles; and identifying the origin and migration patterns for golden eagles over-wintering in southeastern and south-central New Mexico. The information from this study will greatly strengthen the ability to predict potential risks and help develop effective mitigation strategies to reduce potential effects.

\section{Strategic Goal D. Accelerate Technological Innovation to Enhance Science-Based Decision Making}

CRU research in 2016 included 14 projects for development of Advanced Technologies at 13 Units and 27 projects for development and application of Decision Science tools at 14 Units. For example, the Oregon Unit is developing noninvasive methods to monitor burrow-nesting seabird populations:

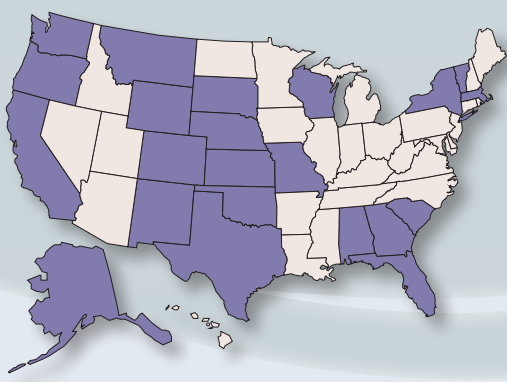

Figure 6. States with Cooperative Fish and Wildlife Research Units with 2016 research projects focusing on the science themes of Advanced Technologies and Decision Science.
Populations of surface-nesting seabirds can be monitored using aerial photography and visual counts; however, monitoring of burrow-nesting species is more challenging, especially on offshore islands that are difficult to access. This study plans to develop, test, and validate multiple new, efficient, and minimally invasive techniques to monitor populations of a representative burrownesting seabird, Leach's Storm-Petrel (Oceanodroma leucorhoa). Researchers are using upward viewing remote cameras and acoustic recorders to generate abundance estimates. Through partnerships, these efforts may lead to the design and implementation of a comprehensive inventory and standardized census program for burrow- and crevice-nesting seabirds to obtain a more accurate estimate of populations, monitor population trends, and establish a long-term research program using seabirds as biological indicators of ocean conditions and effects of climate change.

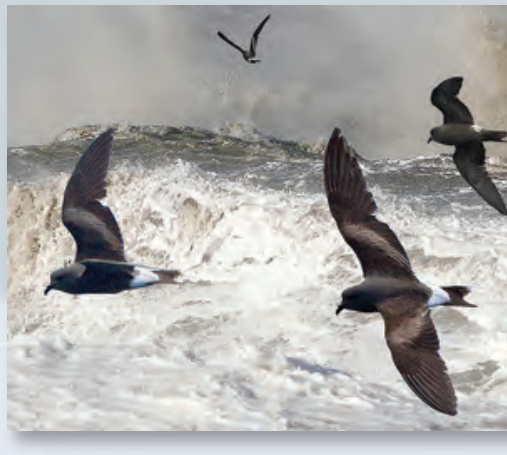

Leach's Storm Petrel from the Crossley ID Guide Britain and Ireland.

Licensed under Creative Commons Attribution-Share Alike 3.0 Unported. 


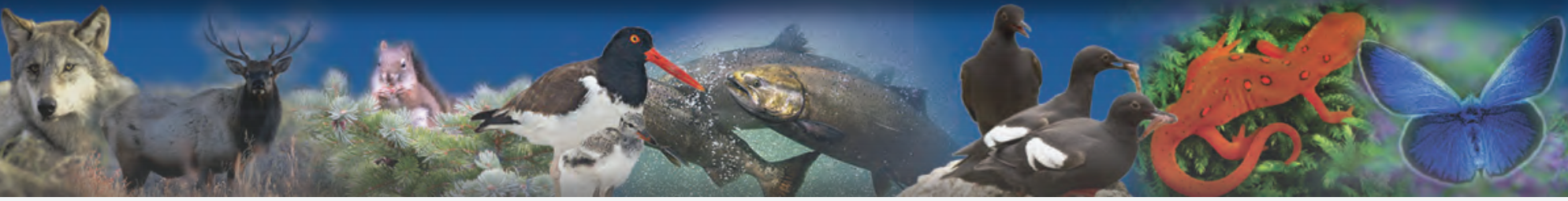

\section{Education and Youth}

In addition to Unit graduate students, university staff and undergraduate students benefit from real-world, experiential learning opportunities that result in attaining a valued professional skillset. All participants emerge from the program uniquely prepared to be effective members of the natural resource workforce. The success of the CRU program's integrated educational approach is evident by the large number of CRU students who now hold important leadership positions in nearly every State and Federal conservation agency.

The CRU program has a unique opportunity within the USGS to recruit individuals from underrepresented segments of society into the fish and wildlife profession. The opportunity to actively participate in research field work often plays an important role in recruiting undergraduates from all ethnic groups to pursue graduate degrees in fish and wildlife programs. CRU reimbursable research funding annually supports a large number of university-based positions, including more than 600 graduate and postgraduate positions (M.S. and Ph.D. students and postdocs) and more than 300 university staff (administrative positions and lab and field technicians). Each year, 80 to 100 graduate students earn advanced (M.S. and Ph.D.) degrees and benefit through direct interactions with funding agency biologists and managers during the course of their research program. In addition, the CRU program continues to develop youth initiatives to create pathways for training, recruitment, and mentoring of underrepresented youth so that future fish and wildlife managers and scientists will be more representative of the public they serve. A new initiative, started in FY 2017, is a pilot partnership program with the USFWS that allows underrepresented CRU graduate and undergraduate students to conduct research on National Wildlife Refuges. Students may participate in research projects designed to provide science-based management decisions that integrate multiple objectives typical of the National Wildlife Refuge System, such as landscape connectivity, fish and wildlife health, human uses, and wildlife population management.

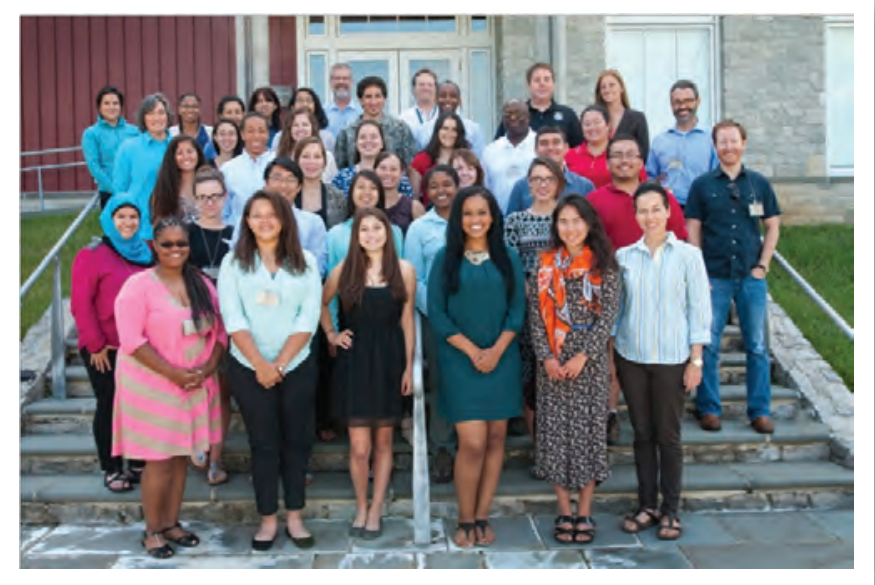

Doris Duke scholars.

Publishing support provided by:

Reston and Rolla Publishing Service Centers

\section{Economic Significance}

CRU research is, and always has been, very applied in nature, as it is typically targeted at harvested, at-risk, or commercially important species managed by the program's State and Federal agency partners. The applied nature of CRU research fits within the USGS strategic goal of "Science to Manage and Sustain Resources for Thriving Economies and Healthy Ecosystems," as annual expenditures in recent years associated with fish and wildlife resources exceeded $\$ 100$ billion dollars annually in the 38 States with Cooperative Fish and Wildlife Research Units.

For the 38 States with Cooperative Fish and Wildlife Research Units, the annual numbers of and expenditures by participants convey the substantial economic, social, and cultural significance of the fish and wildlife resources that the CRU program's research helps to support and manage (U.S. Department of the Interior, U.S. Fish and Wildlife Service and U.S. Department of Commerce, U.S. Census Bureau, 2014):

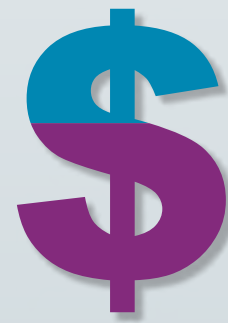

85.8 million citizens participated in hunting, fishing, or wildlife watching activities

$\$ 41.4$ billion was expended by wildlife watchers

\$68.4 billion was expended by hunters and anglers

$\$ \mathbf{1 0 9 . 8}$ billion was expended by the participants

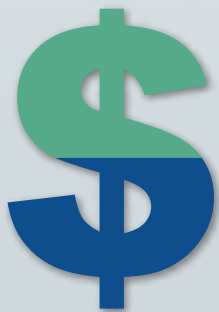

$\$ 161.4$ million total funding

$\$ 80.2$ million in State funding

$\$ 81.2$ million in Federal funding (includes $\$ 37.2$ million reimbursable funding from USGS)

Research funding received over fiscal years 2011-2015.

\section{Reference Cited}

U.S. Department of the Interior, U.S. Fish and Wildlife Service and U.S. Department of Commerce, U.S. Census Bureau, 2014, 2011 national survey of fishing, hunting, and wildlifeassociated recreation: U.S. Department of the Interior, U.S. Fish and Wildlife Service and U.S. Department of Commerce, U.S. Census Bureau report FHW/11-NAT (RV), 161 p., accessed February 1, 2017, at https://www.census.gov/ prod/www/fishing.html.

\section{By Donald E. Dennerline and Dawn E. Childs}

\section{For additional information, contact:}

Cooperative Fish and Wildlife Research Units Program U.S. Geological Survey 12201 Sunrise Valley Drive

Reston, VA 20192

http://www.coopunits.org/

ISSN 2327-6916 (print) ISSN 2327-6932 (online) https://doi.org/10.3133/ss20173022 